\title{
LRRK2 P755L variant in sporadic Parkinson's disease
}

\author{
Hiroyuki Tomiyama · Ikuko Mizuta $\cdot$ Yuanzhe Li $\cdot$ Manabu Funayama \\ Hiroyo Yoshino $\cdot$ Lin Li · Miho Murata · Mitsutoshi Yamamoto • \\ Shin-ichiro Kubo $\cdot$ Yoshikuni Mizuno $\cdot$ Tatsushi Toda $\cdot$ Nobutaka Hattori
}

Received: 20 June 2008/Accepted: 31 August 2008/Published online: 16 October 2008

(C) The Japan Society of Human Genetics and Springer 2008

\begin{abstract}
Parkinson's disease (PD) is a neurodegenerative disorder of unknown etiology with probable involvement of genetic-environmental factors. The majority of PD cases (approximately 90-95\%) are sporadic, while familial cases account for approximately $5-10 \%$ of PD. In a recent report, a heterozygous LRRK2 P755L mutation within LRRK2 exon 19 was found in $2 \%$ of Chinese sporadic PD patients and in $0 \%$ of normal controls or Caucasians, suggesting that the mutation is disease-associated with ethnic specificity. To further evaluate the role of $L R R K 2 \mathrm{P} 755 \mathrm{~L}$ variant in sporadic $\mathrm{PD}$, we performed direct sequencing of $L R R K 2$ exon 19 in
\end{abstract}

H. Tomiyama · Y. Li · L. Li · S.-i. Kubo · N. Hattori $(\bowtie)$ Department of Neurology,

Juntendo University School of Medicine,

2-1-1 Hongo, Bunkyo-ku, Tokyo 113-8421, Japan

e-mail: nhattori@med.juntendo.ac.jp

I. Mizuta $\cdot$ T. Toda

Division of Clinical Genetics,

Osaka University Graduate School of Medicine,

Suita, Japan

I. Mizuta - M. Murata $\cdot$ M. Yamamoto - T. Toda $\cdot$ N. Hattori Core Research for Evolutional Science and Technology

(CREST), Japan Science and Technology Agency,

Saitama, Japan

M. Funayama · H. Yoshino - Y. Mizuno

Research Institute for Diseases of Old Age,

Juntendo University School of Medicine, Tokyo, Japan

M. Murata

Department of Neurology, Musashi Hospital,

National Center of Neurology and Psychiatry, Tokyo, Japan

M. Yamamoto

Department of Neurology,

Kagawa Prefectural Central Hospital, Takamatsu, Japan
501 Japanese sporadic PD patients (male 249, female 252, aged 28-92 years, mean 65.0 years) and 583 controls of the Japanese general population as an extended association study. In this group, we found six patients $(6 / 501=1.2 \%)$ and eight controls of the general population $(8 / 583=1.6 \%)$ with a heterozygous $\mathrm{P} 755 \mathrm{~L}$ variant $\left(P=0.80, \chi^{2}=0.064\right)$. No other variants were found in exon 19 . Together with previous reports, our extended case-controlled study of large sample size suggests that LRRK2 P755L is a non-diseaseassociated polymorphism in PD patients.

Keywords Parkinson's disease - Genetics - PARK8 . Leucine-rich repeat kinase 2 (LRRK2) · Polymorphism . Association study $\cdot$ Japanese $\cdot$ Ethnic background

\section{Introduction}

Parkinson's disease (PD, OMIM \#168600) is the second most common neurodegenerative disorder next to Alzheimer's disease. The clinical features are characterized by levodopa-responsive parkinsonism, such as rigidity, resting tremor, bradykinesia, and postural instability. Although the cause of PD remains unclear, genetic-environmental interaction is suggested for the development of the disease. One of the autosomal-dominant forms of PD, PARK8, was originally mapped from a Japanese Sagamihara family (Funayama et al. 2002) and LRRK2 (PARK8; leucine-rich repeat kinase 2 , OMIM $* 609007)$ was identified as the causative gene for PARK8-linked PD (Paisán-Ruíz et al. 2004; Zimprich et al. 2004). Among LRRK2 mutations, the most common LRRK2 G2019S mutation in North Africans and Ashkenazi Jews has shown ethnic differences among Caucasian, Japanese, and Chinese (Nichols et al. 2005; Gilks et al. 2005; Lesage et al. 2006; Tomiyama et al. 
2006; Tan et al. 2005). On the other hand, LRRK2 G2385R variant has recently been found the most common genetic risk factor among Chinese and Japanese, but not Caucasians (Di Fonzo et al. 2006; Funayama et al. 2007; Tan et al. 2007; Farrer et al. 2007). Moreover, in a recent report (Wu et al. 2006), a heterozygous LRRK2 p.P755L (c.2264c $>t$, rs34410987) mutation within LRRK2 exon 19, corresponding to a predicted ankyrin-repeat-like domain of LRRK2, was found in 2\% (12/598) of Chinese sporadic PD and $0 \%(0 / 765)$ of Chinese normal controls, suggesting its association with the disease. However, LRRK2 P755L was reported as a polymorphism (3\% of 92 normal controls) in the dbSNP database of Taiwanese. Thus, to determine the frequency and the role of LRRK2 P755L in Asian PD, we screened for LRRK2 exon 19 in Japanese sporadic PD patients.

\section{Subjects and methods}

The nucleotide sequences of LRRK2 exon 19 were determined by direct sequencing in 501 sporadic Japanese PD patients and 583 controls of the Japanese general population (Table 1). All blood samples and clinical information were obtained by the attending neurologists after obtaining informed consent from their patients. The study was approved by the ethics review committees of Juntendo and Osaka Universities. Diagnosis of PD was made by the attending neurologists based on the presence of parkinsonism and good response to anti-PD treatment. Controls of the Japanese general population were evaluated by neurologists to ensure none of them had PD. DNA was prepared using standard methods. They were amplified by polymerase chain reaction (PCR) of exon 19 and sequenced using BigDye Terminator Chemistry and ABI310 and 3130 Genetic Analyzer (Applied Biosystems, Foster City, CA). Sequences of the primers, conditions of PCR, and conditions of sequencing were based on a previous report (Zimprich et al. 2004).

Table 1 Profile of analyzed samples in this study

${ }^{\text {a }}$ Data are mean $\pm \mathrm{SD}$ (range)

\section{Results}

We found 6 patients $(6 / 501=1.2 \%)$ and 8 controls of the Japanese general population $(8 / 583=1.6 \%)$ with a heterozygous $\mathrm{P} 755 \mathrm{~L}$ variant $(P=0.80$, odds ratio $=1.15$, 95\% CI: $\left.0.40-3.32, \chi^{2}=0.064\right)$ in $L R R K 2$ exon 19 (Table 2). No other variants were found in exon 19.

\section{Discussion}

The purpose of the present study was to clarify the role of an ethnic-specific variant in the causative gene for PD. Although PD is considered a heterogeneous disease with genetic-environmental interaction, some cases certainly exhibit a Mendelian-inherited disease or are associated with strong genetic and ethnic background. Indeed, the reported frequency of $L R R K 2$ G2385R was higher in Asian sporadic PD patients than in controls (Di Fonzo et al. 2006; Funayama et al. 2007; Tan et al. 2007), although this is not the case in Caucasians. Moreover, Wu et al. (2006) in Nanjing, China, recently reported that a heterozygous LRRK2 P755L mutation was found in 2\% (12/598) of Chinese sporadic PD and 0\% (0/765) of normal controls, whereas none (0/463) of the Caucasian PD patients had this mutation (Deng et al. 2007), suggesting ethnic differences, like LRRK2 G2385R. However, our results of large casecontrolled study in Japanese revealed that LRRK2 P755L is a non-disease associated polymorphism. Consistent with our data, this variant was present at similar frequency in Taiwanese PD patients $(7 / 578=0.99 \%)$ and Taiwanese normal controls $(10 / 339=0.97 \%)($ Di Fonzo et al. 2006). Furthermore, the latest report in the Chinese population in Singapore showed the absence of segregation and association of P755L with PD (case $4 / 204=2.0 \%$, control 6/ $235=2.6 \%, P=0.76$ ) (Tan et al. 2008). These findings might be based on ethnic or native differences in human migration history or human genetics.

We reported previously that the most common LRRK2 G2019S mutation in Mendelian-inherited and sporadic PD

\begin{tabular}{|c|c|c|c|}
\hline & Total sample, $n(\%)$ & $501(100)$ & $583(100)$ \\
\hline & Male, $n(\%)$ & $249(49.7)$ & $312(53.5)$ \\
\hline & Female, $n(\%)$ & $252(50.3)$ & $271(46.5)$ \\
\hline & Age at sampling (years) ${ }^{\mathrm{a}}$ & $65.0 \pm 9.6(28-92)$ & $45.0 \pm 17.0(21-98)$ \\
\hline & Male $^{\mathrm{a}}$ & $64.3 \pm 10.2(28-92)$ & $43.6 \pm 15.0(22-92)$ \\
\hline & Female $^{\mathrm{a}}$ & $65.4 \pm 9.9(28-92)$ & $46.8 \pm 19.0(21-98)$ \\
\hline & Age at onset (years) ${ }^{a}$ & $58.0 \pm 10.5(20-88)$ & \\
\hline & Male $^{\mathrm{a}}$ & $57.7 \pm 10.9(20-88)$ & \\
\hline Data are mean $+\mathrm{SD}$ (range) & Female $^{\mathrm{a}}$ & $58.3 \pm 10.1(25-82)$ & \\
\hline
\end{tabular}


Table 2 Allele frequency of LRRK2 c. 2264C > T (p. P755L) in Japanese patients with Parkinson's disease and controls of general population

\begin{tabular}{|c|c|c|c|c|c|c|c|}
\hline & \multicolumn{3}{|c|}{ Genotype, $n(\%)$} & \multicolumn{4}{|l|}{ Allele, $n(\%)$} \\
\hline & $\mathrm{C} / \mathrm{C}$ & $\mathrm{C} / \mathrm{T}$ & $\mathrm{T} / \mathrm{T}$ & $\mathrm{C}$ & $\mathrm{T}$ & $\chi^{2 \mathrm{a}}$ & OR $(95 \% \mathrm{CI})$ \\
\hline Patients $(n=501)$ & $495(98.8)$ & $6(1.2)$ & $0(0)$ & $996(99.4)$ & $6(0.6)$ & 0.06 & $1.15(0.40-3.32)$ \\
\hline Controls of general population $(n=583)$ & $575(98.6)$ & $8(1.4)$ & $0(0)$ & $1,158(99.3)$ & $8(0.7)$ & & \\
\hline
\end{tabular}

${ }^{a}$ Compared with the control

$O R$ odds ratio, $C I$ confidence interval

was rare in Asians compared to North Africans or Caucasians (Tomiyama et al. 2006). LRRK2 variants are reported to spread worldwide with some ethnic differences among each variant, such as R1441G, R1441C, R1441H (exon 31, ROC domain), G2019S, I2020T (exon 41, MAPKKK domain), and G2385R (exon 48, WD40 domain) (Mata et al. 2005). Since $L R R K 2$ consists of as many as 51 exons, it is important to decide which exon(s) of this gene should be screened first for efficient analysis of mutation in patients with various ethnic backgrounds. In this regard, $L R R K 2$ exon 41 and 31 are reasonable to be screened first; however, exon 19 is not likely a candidate exon for causative mutation screening in PD. In addition, although MAPKKK and ROC domain are reported to be associated with kinase activity of LRRK2 (Paisán-Ruíz et al. 2004; Zimprich et al. 2004; Smith et al. 2006), the existence and the role of the predicted ankyrin repeat-like domain in LRRK2 have not been established yet.

So far, LRRK2 P755L as well as G2385R variants have been found in only Chinese, Taiwanese, and Japanese (Asians) with similar frequencies in some Asians, but have not been found in Caucasians. Thus, these variants could occur independently in very ancient Asians with a single founder effect (Farrer et al. 2007). Although the HapMap project has been very successful, the presence of ethnic differences among LRRK2 variants such as G2019S, R1441G, G2385R, and P755L suggest that further establishment of ethnic-specific or native-specific data is essential for more accurate SNP analyses and genome-wide association studies.

\section{Conclusion}

Our extended association study in Japanese with large sample size suggests that $L R R K 2 \mathrm{P} 755 \mathrm{~L}$ is a non-diseaseassociated polymorphism in PD patients.

Acknowledgments The authors thank all the participants. The authors also thank Ms. Yuko Nakabayashi and Ms. Yoko Imamichi for the excellent technical assistance. This work was supported by a grant from Core Research for Evolutional Science and Technology (CREST) of the Japan Science and Technology Agency (JST) and by Grants-in-Aid from the Research Committee of CNS Degenerative Diseases, the Ministry of Health, Labor, and Welfare of Japan.

\section{References}

Deng H, Le W, Huang M, Xie W, Pan T, Jankovic J (2007) Genetic analysis of LRRK2 P755L variant in Caucasian patients with Parkinson's disease. Neurosci Lett 419:104-107

Di Fonzo A, Wu-Chou YH, Lu CS, van Doeselaar M, Simons EJ, Rohé CF, Chang HC, Chen RS, Weng YH, Vanacore N, Breedveld GJ, Oostra BA, Bonifati V (2006) A common missense variant in the LRRK2 gene, Gly2385Arg, associated with Parkinson's disease risk in Taiwan. Neurogenetics 7:133-138

Farrer MJ, Stone JT, Lin CH, Dächsel JC, Hulihan MM, Haugarvoll $\mathrm{K}$, Ross OA, Wu RM (2007) Lrrk2 G2385R is an ancestral risk factor for Parkinson's disease in Asia. Parkinsonism Relat Disord 13:89-92

Funayama M, Hasegawa K, Kowa H, Saito M, Tsuji S, Obata F (2002) A new locus for Parkinson's disease (PARK8) maps to chromosome 12p11.2-q13.1. Ann Neurol 51:296-301

Funayama M, Li Y, Tomiyama $\mathrm{H}$, Yoshino $\mathrm{H}$, Imamichi $\mathrm{Y}$, Yamamoto M, Murata M, Toda T, Mizuno Y, Hattori N (2007) Leucine-rich repeat kinase 2 G2385R variant is a risk factor for Parkinson disease in Asian population. NeuroReport 18:273-275

Gilks WP, Abou-Sleiman PM, Gandhi S, Jain S, Singleton A, Lees AJ, Shaw K, Bhatia KP, Bonifati V, Quinn NP, Lynch J, Healy DG, Holton JL, Revesz T, Wood NW (2005) A common LRRK2 mutation in idiopathic Parkinson's disease. Lancet 365:415-416

Lesage S, Durr A, Tazir M, Lohmann E, Leutenegger AL, Janin S, Pollak P, Brice A, French Parkinson's Disease Genetics Study Group (2006) LRRK2 G2019S as a cause of Parkinson's disease in North African Arabs. N Engl J Med 354:422-423

Mata IF, Kachergus JM, Taylor JP, Lincoln S, Aasly J, Lynch T, Hulihan MM, Cobb SA, Wu RM, Lu CS, Lahoz C, Wszolek ZK, Farrer MJ (2005) Lrrk2 pathogenic substitutions in Parkinson's disease. Neurogenetics 17:1-7

Nichols WC, Pankratz N, Hernandez D, Paisán-Ruíz C, Jain S, Halter CA, Michaels VE, Reed T, Rudolph A, Shults CW, Singleton A, Foroud T, Parkinson Study Group-PROGENI investigators (2005) Genetic screening for a single common LRRK2 mutation in familial Parkinson's disease. Lancet 365:410-412

Paisán-Ruíz C, Jain S, Evans EW, Gilks WP, Simón J, van der Brug M, López de Munain A, Aparicio S, Gil AM, Khan N, Johnson J, Martinez JR, Nicholl D, Carrera IM, Pena AS, de Silva R, Lees A, Martí-Massó JF, Pérez-Tur J, Wood NW, Singleton AB (2004) Cloning of the gene containing mutations that cause PARK8-linked Parkinson's disease. Neuron 44:595-600

Smith WW, Pei Z, Jiang H, Dawson VL, Dawson TM, Ross CA (2006) Kinase activity of mutant LRRK2 mediates neuronal toxicity. Nat Neurosci 9(10):1231-1233

Tan EK, Shen H, Tan LC, Farrer M, Yew K, Chua E, Jamora RD, Puvan K, Puong KY, Zhao Y, Pavanni R, Wong MC, Yih Y, Skipper L, Liu JJ (2005) The G2019S LRRK2 mutation is uncommon in an Asian cohort of Parkinson's disease patients. Neurosci Lett 384:327-329 
Tan EK, Zhao Y, Skipper L, Tan MG, Di Fonzo A, Sun L, FookChong S, Tang S, Chua E, Yuen Y, Tan L, Pavanni R, Wong MC, Kolatkar P, Lu CS, Bonifati V, Liu JJ (2007) The LRRK2 Gly2385Arg variant is associated with Parkinson's disease: genetic and functional evidence. Hum Genet 120:857-863

Tan EK, Lim HQ, Yuen Y, Zhao Y (2008) Pathogenicity of LRRK2 P755L variant in Parkinson's disease. Mov Disord (online 8 Feb 2008)

Tomiyama H, Li Y, Funayama M, Hasegawa K, Yoshino H, Kubo S, Sato K, Hattori T, Lu CS, Inzelberg R, Djaldetti R, Melamed E, Amouri R, Gouider-Khouja N, Hentati F, Hatano Y, Wang M, Imamichi Y, Mizoguchi K, Miyajima H, Obata F, Toda T, Farrer MJ, Mizuno Y, Hattori N (2006) Clinicogenetic study of mutations in LRRK2 exon 41 in Parkinson's disease patients from 18 countries. Mov Disord 21:1102-1108

Wu T, Zeng Y, Ding X, Li X, Li W, Dong H, Chen S, Zhang X, Ma G, Yao J, Deng X (2006) A novel P755L mutation in LRRK2 gene associated with Parkinson's disease. NeuroReport 17:18591862

Zimprich A, Biskup S, Leitner P, Lichtner P, Farrer M, Lincoln S, Kachergus J, Hulihan M, Uitti RJ, Calne DB, Stoessl AJ, Pfeiffer RF, Patenge N, Carbajal IC, Vieregge P, Asmus F, MüllerMyhsok B, Dickson DW, Meitinger T, Strom TM, Wszolek ZK, Gasser T (2004) Mutations in LRRK2 cause autosomal-dominant parkinsonism with pleomorphic pathology. Neuron 44:601607 